\title{
Lubricating culture awareness and critical thinking through humour
}

\author{
Aleksandar Takovski \\ AAB College, Republic of Kosovo \\ aleksandar.takovski@universitetiaab.com
}

\begin{abstract}
There is an ample evidence supporting the benefits of instructional humour, including increased attention and interest, information retention and learning speed, more productive learning environment, a more positive image of the instructor, more efficient acquisition of linguistic and cultural competencies, an increased conversational involvement, enhanced cultural awareness and more stimulated critical thinking. However, most of the research findings rely on what is termed appropriate humour, such as puns, jokes, anecdotes, and alike, while potentially offensive humour that relates to sexual, ethnic, religious, and political identity is generally labelled inappropriate and advised to be avoided in the classroom. It is in this particular context that this study seeks to test the potential of such humour, sexual and ethnic in particular, to act as a tool of increasing cultural awareness and stimulate critical thinking among university students. To do so, the study relies on an experimental class design combining in-class and extracurricular activities created by using sexual and ethnic humour samples.
\end{abstract}

Keywords: instructional humour, critical thinking, cultural awareness.

\section{Introduction}

The burgeoning literature on the use of humour in education has offered ample evidence of its uses and effects. It has been demonstrated that humour, amusement, and play can reduce anxiety in the classroom, while at the same increasing attention and interest (Sudol 1981; Gorham 1988; Hill 1988; Neuilip 1991). There is evidence that humour can enhance learning (Berk 2002; Garner 2003; Hackathorn et al. 2011) by increasing learning speed (Gorham \& Cristophel 1990; Torok et al. 2004) or by helping students retain novel information (Torok et al. 2004; Garner 2006). In addition, humour can reduce test anxiety and improve test performance (Berk 2000; Berk \& Nanda 2006), improve problem-solving skills and stimulate students to display creative and critical thinking skills (Dorman \& Biddle 2006; Wanzer et al. 2010). Within the context of language learning, humour can foster conversational involvement (Davies 2003), expand communicative repertoires (Bell \& Pomerantz 2014) and contribute to the acquisition and practice of various linguistic, communicative and cultural competences (Tratchtenber 1979; 
Berwald 1992; Deneire 1995; Bell 2009; Bell \& Pomerantz 2014). It is these two instructional humour potentials - the development of cultural awareness and the stimulation of critical thinking - that this study seeks to explore in more detail.

Studies on the relation between humour and culture consider humour, jokes in particular, to be embodiments of culture (Trachtenberg 1977) and mirrors of sociocultural practices (Schmitz 2002) which help learners gain insight into the target culture (Trachtenberg 1977; Bell 2009). To understand them, learners need to know the sociolinguistic rules underpinning their production and learn to recognise the cultural references used in humour. The validity of the assumptions notwithstanding, some of the questions these studies fail to successfully address include: What are the particular methods of teaching culture through humour? What kind of cultural insight does humour offer? Is it limited to the part necessary to understand the joke? Can humour be used to stage a complex, critical debate on culture as suggested by Schmitz (2002: 104)? Answers to these questions are largely unsatisfactory because most studies use the notion of "culturally acceptable" humour to merely illustrate its dependence on culture.

In this manner, the joke "Do you know what I got for Father's Day? - The bill for Mother's Day" (Schmitz 2002) illustrates the cultural dependency of humour, implying the necessity of possessing cultural information about Father's and Mother's Day in order to understand it. The question, however, is whether such jokes can open up a space for critical, more complex understanding of culture, and thus "make use of the opportunity to have students reflect critically about the target culture" (Schmitz 2002: 104). The answer is negative mostly because jokes like these operate on acceptable, non-controversial units of cultural encyclopaedia such as Father's Day that can be effectively used to critically examine culture only if exploited systematically. Questions such as why is Father's Day celebrated, how this reflects, perpetuates or challenges social attitudes on fatherhood, what factors underpin the creation of these attitudes, to what extent they are biased and how, are some of the questions that need to be raised in order to gain a fuller understanding of the phenomenon. Moreover, to understand culture in its totality, potentially controversial issues need to be discussed as well. Issues such as sexuality and ethnicity that are traditionally avoided in pedagogy carry a great potential to raise cultural awareness and stimulate the critical thought.

Such contents are thought provoking, as they relate to culturally sensitive issues articulated through stereotypes and prejudices. Understanding their existence in the larger socio-historic context can be achieved, I argue, by thinking critically of the processes of their creation, a process in which humour can act as a valuable lubricant to decrease inhibition of discussing taboos and encourage analytical discussion. What makes humour a viable tool to accomplish this end is the fact that it encapsulates cultural views, beliefs, and perceptions often in a reductionist manner in the form of stereotypes, clichés, and controversies. Thus, a critical approach to humour will not only illustrate cultural reductions encoded humorously, but will also question the very formation of cultural realities, beliefs, values, and prejudices created by culture and present in humour. As such, critical examination does not only result in understanding the other, but also allows one to reflect on one's own culturally formed perceptions and prejudices about the other. Understanding the other and questioning oneself constitute the backbone of critical thinking, which can be stimulated by the use of humour, as this study contends. Introducing biting humour in a well-planned, structured, and monitored way is the manner to achieve these ends.

To test this assumption, the study relies on an experimental methodological design consisting of a series of in-class and extracurricular activities created by using two types of humorous contents - sexual and ethnic. The activities were undertaken with a group of university students in a process where different variables were tested in order to establish their relevance to the achievement of the objectives. 
To map the place of this study in the burgeoning field of instructional humour, the following section first briefly outlines the research on humour's effects on learning in order to provide a theoretical background of the study. It then discusses the use of humour to teach language and culture in order to identify its shortcomings. Finally, it outlines arguments and recommendations against the use of certain types of humour (sexual and ethnic in particular) counter evidence.

\section{Humour and teaching}

\subsection{The psychological effects of humour}

Findings on the instructional humour effects are inconsistent (see Banas et al. 2010; Wanzer et al. 2010 for more details). On the one hand, it has been demonstrated that humour can create stimulating, more productive learning environments by increasing the closeness between the teacher and the students and create trustworthy relationships between them (Gorham 1988; Gorham \& Cristophel 1990; Neuliep 1991). Additionally, humour can contribute to a positive image and evaluation of the teacher (Bryant et al. 1980; Torok et al. 2004), can reduce tension, stimulate interest, and facilitate information retention (Sudol 1981; Hill 1988; Neuilip 1991; Teslow 1995), can make learning more enjoyable (Berwald 1992; Medgyes 2001; Schmitz 2002), increase motivation and learning (Bryant \& Zillmann 1989; Wanzer \& Frymier 1999; Frymier \& Weser 2001;), engage students in the learning process and increase learning speed (Berk 1996, 2002; Garner 2003; Hackathorn et al. 2011).

On the other hand, humour may not have any effect upon information acquisition and retention whatsoever (Gruner 1967; Wanzer et al. 2006; Houser et al. 2007). Moreover, it may distract the teaching of core concepts (Zillmann et al. 1980) and make children confused about the humorous distortions and factual information (Bryant \& Zillmann 1989). Certain types of instructional humour may have negative consequences as well (Gorham \& Christophel 1990; Stuart \& Rosenfeld 1994; Torok et al. 2004). Sarcastic humour, for instance, can confuse students who are not listening carefully or are not reading non-verbal cues appropriately (Zillman et al. 1984), while aggressive humour can create an uncomfortable learning environment (Saroglou \& Scariot 2002; Torok et al. 2004). Therefore, in order for humour to positively contribute to an enjoyable learning environment and facilitate learning, research suggests that it needs to be appropriate. Appropriate humour is neither aggressive nor offensive because it is not based on race, ethnicity, sex, political affiliation etc. (Frymier et al. 2008), nor it embodies an incongruity that cannot be perceived and resolved (Wanzer et al. 2010). While humour which is difficult to process can certainly cause frustration and failure, humour based on potentially controversial cultural constructs such as sex, ethnicity, politics, and religion may be reworked into an appropriate format to teach and discuss culture and thus increase cultural awareness and stimulate critical thinking, the two objectives this study seeks to pursue.

\subsection{Use of humour to teach language and culture}

Studies have argued that humour can be used to introduce and practice different linguistic structures and teach learners the culture underpinning humour (Cook 2000; Broner \& Tarone 2001; Belz \& Reinhardt 2004; Bell 2005). While many studies have successfully demonstrated how humour can contribute to the development of linguistic competencies, others have failed to demonstrate how humour can be used as a didactic framework to learn and discuss culture.

Trachtenberg (1979) sees jokes as rule-governed mini lessons in grammar, vocabulary, and speech patterns that embody culture and, as such, they can serve as effective means of promoting fluency, illustrate and instruct sociolinguistic rules, and help students appreciate and understand cultural values. While the author successfully demonstrates how jokes are used to introduce and 
practice new vocabulary, syntactic patterns, and general comprehension, Treachtenberg fails to convincingly demonstrate how cultural jokes can illustrate cultural values. The example Trachtenberg uses is the following:

Did I tell you about my Uncle Albert? (No.) Well, he finally figured out a way to get rid of his garbage during the garbage strike. (How?) He just gift-wraps it, and puts it in the back of his car.

(Trachtenberg 1979: 94)

It is obvious that full understanding and appreciation of the joke requires familiarity with the American urban context and the garbage strikes. However, this information only helps understand the joke, but not the underpinning cultural values. Without a more elaborate discussion, it remains vague what values are at stake here: is it the values of cleanness, cunningness, or other? In a similar vein, Deneire (1995) argues that humour can reinforce linguistic and cultural competence if introduced at the right time. According to Deneire, exposure to L2 jokes helps sensitise learners of the L1 and L2 to differences occurring on multiple structural levels (phonological, morphological, lexical, and syntactic). Deneire (1995: 293) explains that "shared knowledge is necessary for the perception of the joke, the referential content of the joke itself, and the process by which the joke is constructed around its object", further arguing that "to define a joke is to define the society in which the joke occurs". Unfortunately, Deneire offers no detailed account of how this can be achieved. Similar objections can be raised against the assumption that cultural jokes, ethnic jokes included, serve as mirrors of sociocultural practices (Schmitz 2002: 103), and thus allow "students to reflect critically about the target culture" (Schmitz 2002: 104). However, with no examples or discussion on how to encourage this critical reflection, these otherwise valid assumptions remain unexploited. Similarly, without embedding the joke in a more insightful discussion about the culture that has produced it, the following joke

Do you know what I got for Father's Day?

No, what?

The bill for Mother's Day.

(Schmitz 2002: 103)

merely hints to the cultural rootedness and chronological ordering of the two events rather than creating an opportunity to critically reflect upon the culture that has produced the two events joked about. Moreover, Schmitz completely abandons the suggestion that ethnic humour offers valuable cultural material to be inspected. Part of the problem of not using this link (between culture and humour) more efficiently is hinted by Bell (2009: 249-251) who points to the problem of the extent to which humour in practice is used to illuminate L2 culture and not merely to "add an extra layer of meaning to be grappled with, thus obscuring the point". In this respect, Bell (2009: 249) reasons, "while humour is frequently touted as a means of facilitating cultural understanding, opportunities to discuss culture deeply and critically may get overlooked or avoided". Insightful as it is, Bell's assumptions, unfortunately, do not raise the issue of why such an opportunity has been neglected and how to use humour to introduce and discuss culture more critically. Two possible answers are: a) cultural aspects of language learning are traditionally neglected at the expense of linguistic ones, and b) pedagogy and instructional humour research excludes some types of humour as potentially harmful, the reasons for which are briefly outlined in the next section.

\subsection{Appropriate and inappropriate humour}


Based on the distinction between appropriate and inappropriate instructional humour, research has suggested humour types to be used or avoided in the classroom. Humorous genres such as stories, jokes, puns, word play, non-verbal humour, impersonation, teacher's self-disparaging humour, and generally humour that does not target students, are considered appropriate (Gardner 2006; Wanzer et al. 2006; Banas et al. 2011), while humour that is aggressive and/or offensive such as sexual humour, ethnic humour, political humour, sarcasm, profanity, is deemed inappropriate (Berk 2002; Torok et al. 2004; Wanzer et al. 2006; Frymeier et al. 2008). Such humour, research argues, can result in withdrawal, resentment, anger, tension (Berk 2002), and generally create an uncomfortable learning environment (Saroglou \& Scariot 2002; Torok et al. 2004). Of particular interest to this study are the arguments raised against the use of sexual and ethnic humour. In this respect, Deneire argues that

[s]exual humour is quite naturally excluded from the classroom for both psychological and social reasons. While the main function of sexual humour is, according to Freud, to release repressed feelings in what he calls "tendentious humour", education has often seen its role as a repressor of these sexual and aggressive urges and considered it its duty to transform these into more sublime desires.

Deneire (1995: 287)

On the other hand, intergroup jokes, ethnic jokes included, are dismissed from the classroom because they can be offensive and can make "members of a community often believe that this kind of humour does contain valid cultural information" (Deneire 1995: 288) and, in consequence, "we cannot assume that listeners will systematically doubt the information contained in the text of inter-ethnic jokes" (Deneire 1995: 288).

Avoiding sexual and ethnic humour in order to avoid offence and negatively impact the process of teaching/learning is reasonable, and yet such recommendation should and can be taken with a grain of salt, while the possibility of using inappropriate humour should be considered. One of the reasons to dismiss appropriate humour is that it may not offer any material for critical examination of culture. Examples such as puns are tokens of linguistic humour which are usually not illustrative of culture. On the other hand, topics such as sex, ethnicity, and politics are the atoms of cultural intimacy that define and differentiate cultures. Sex is the ultimate anxiety, and a cultural contingency overloaded with multiple interpretations that need critical disentanglement. Ethnicity, moreover, as constructed in jokes, is reduced to negative stereotypes. In this respect, Deneire is right to assert that ethnic jokes offer little culturally valid information, being themselves reductions of cultural complexity, and that listeners will perhaps not doubt this reduction. However, avoiding stereotypes merely allows their perpetuation, and education in this context should play the key role in fighting against them. In this respect, university should not suppress or transform human emotions and drives and avoid sensitive topics. Instead, it should offer an access to educated discussions on all human-defining aspects along with the knowledge and skills necessary to do so. Exposing learners to sexual and ethnic humour does not necessitate perpetuation of stereotypes, but allows their questioning, and a more insightful understanding of culture. Based on the assumptions raised, I argue that critical pedagogy and critical thinking are appropriate conceptual frameworks to develop a pedagogical approach to the use of sexual and ethic humour that is acceptable to pedagogical mainstream, while at the same time offers the opportunity to develop critical thinking skills and cultural awareness.

\subsection{Critical approach to instructional humour}

Drawing on Marcuse's Critical Theory and the notions of inequality, oppression, and hegemony, critical pedagogy considers teaching a political act that aims to awake learners and emancipate 
them from oppression by helping them develop critical consciousness and gain socially transformative potential (Freire 1968; Giroux 1983, 1988; Shor 1992). One of the means to achieve this end is through an anti-bias curriculum that challenges prejudices such as sexism, nationalism, and homophobia, and relies on the development of critical reading and speaking skills. Such skills are necessary to go beyond the surface meaning of texts, first impressions, dominant myths, and examine in depth the claims made. Identifying flaws in reasoning and the ability to address them comprehensively are essential in these processes. In doing so, critical pedagogy encourages critical examination of knowledge, in addition to exploring the dialogic relationships between teaching and learning, which, according to critical pedagogists, is a continuous process of 'unlearning', 'learning', and 'relearning'. These processes enable the development of self-awareness and self-criticality by raising the awareness of the constructed nature of knowledge, including cultural views, beliefs, and stereotypes. Critical thinking, in this context, I argue, is a convenient tool to deconstruct old, biased knowledge, and construct new one.

Although critical thinking is a vast area of research (see Mason 2008; Moon 2008) that highlights different aspects of the cognitive processes involved, and offers different definitions, for economic reasons I shall focus only on three aspects of the phenomenon: questioning, production of new knowledge, and self-reflection. In this context, Facione (2011) considers critical thinking to be "a purposeful self-reflective judgment which rests on interpretation, inference, self-regulation, analysis, explanation, evaluation”. The same aspects are also foregrounded in the definition by Judge et al. (2009), according to which critical thinking is "thinking about your own thinking, willing to question own views, honest in facing one's own bias, flexible in considering alternatives, willing to reconsider and review ideas/opinions".

The way humour can contribute to the development of criticality, self-reflection, and production of new knowledge is by a critical examination of the stereotypes and reductions present in humour, trying to understand their construction, motives, and possible effects. In practical terms, a way to accomplish this is by answering questions such as the following: What stereotypes are present in humour? How are these constructed, what cultural beliefs underpin their construction, are they fallacious, what are their targets, what is their purpose, who appreciates such humorous construction and why? How can we challenge sexually oppressive views? Or ethnically discriminative views? Deneire's (1995: 287) assumption that "ethnic jokes should be excluded because we cannot assume that listeners will systematically doubt the information contained in the text of inter-ethnic jokes" can serve as a starting point. Educators should facilitate and scaffold learners' critical understanding of these processes by helping them start doubting these pieces of information. In this respect, I argue, it is teachers' duty to make listeners systematically doubt such information and to try to prevent the perpetuation of stereotypes not by keeping students safely away from them, but, on the contrary, by exposing them to stereotypes. One possible way to accomplish this is to use sexual and ethnic humour in a carefully designed pedagogical framework, as presented in the next two sections.

\section{Method}

\subsection{Context and participants}

To achieve the objective of critically deconstructing cultural givens (i.e. culturally biased knowledge) by means of stimulating critical thinking, I have created an experimental class design consisting of several in-class and extracurricular activities based on sexual and ethnic humour samples offered to a group of university students. 
Participants were second year students from the South East European University, North Macedonia, enrolled at the Communication Science Department who took the course "English for Specific Purposes for international communication" in the winter semester of 2014. The group consisted of 12 students aged between 20 and 29, the majority of which were ethnic Albanians (10) and two ethnic Macedonians, eight females and four males. Their level of English proficiency ranged from high intermediate to advanced. The small size of the group offers the possibility for an in-depth examination of students' reactions, attitudes, and thoughts on the subject of sexual and ethnic humour. The class experiment additionally relies on their existent skills of argumentation, persuasion, and intercultural communication gained from their majors, such as diplomacy, negotiation, and rhetoric. Prior to the experiment, all students were informed about the ethical aspects of their involvement and their unanimous consent in written form was obtained. The experimental design is typically divided into two sets of activities: those based on sexual humour (Examining Sexuality) and activities based on ethnic humour (Examining Ethnicity).

\subsection{Class materials and activities}

\subsubsection{Unlearning sexuality}

To critically examine the subject of sexuality, five video samples were selected to design inclass and extracurricular activities. The samples include: a) an episode of the American sitcom Broad City (Broad City 2014), b) the "Sex education" sketch (Monty Python 1983), c) an episode of the American animation South Park (South Park 2010), d) a televised stand-up act by the American comedian George Lopez (Lopez 2010), and e) a stand-up act by the comedian Margaret Cho (Cho 2009).

Prior to watching the videos, the students were involved in two activities: a) an introductory discussion on sexuality and its cultural formation intended to raise students' awareness about the subject, elicit background knowledge, and serve as an introductory framework for further discussion, and b) an evaluation of five stereotype-based statements related to the videos in order to identify potential prejudices held by students, and introduce them to the video materials (summaries of the videos and the manner they underpin the statements analysed are provided in Appendix 1). The activity aimed to register the scope and the contents of students' reactions to the stereotypes in order to measure weather and how students question/challenge the stereotypes and if such questioning leads to the creation of new knowledge and potential self-reflection (the three key aspects of critical thinking). After watching the videos, students were presented with three sets of follow-up, self-reflecting questions in order to register change in attitudes, reflect upon their own judgement, and evaluate the role of humour in the processes. This helped register potential changes in attitudes occurring as a result of exposure to the videos and it helped ascertain the effect of the video and the activities as the stimuli of critical thinking (creation of new knowledge and self-reflection). The questions and five statements with summarised answers are reported in Section 4.1.

\subsubsection{Unlearning ethnicity}

A second set of humour-based activities was designed to examine students' awareness and boost critical re-examination of ethnic stereotypes in humour. The first activity was an online research students undertook in order to seek information about four randomly selected cultures that were humour targets of the jokes discussed in class (Mexican, Polish, Estonian, and Jewish). In addition, students were asked to collect ethnic stereotypes about these cultures. After reporting the findings in class, the students were handed a questionnaire with a list of four ethnic jokes 
targeting the selected cultures and questions asking them to identify the stereotypes present in jokes, express their attitude, and critically discuss the formation of stereotypes and potentially challenge/question them using the newly acquired information. In the final activity, students were asked to use the jokes from the questionnaire, substitute the targets with their own ethnicity and discuss the outcome by comparing the two cultures and commenting on the validity of applying the stereotype to the new hypothetical context and the new target. The purpose of the discussion was to: a) stimulate critical reflection on stereotypes, b) raise the awareness about their own prejudices, c) synthesise old and new knowledge, and d) encourage critical judgement.

\section{Results}

\subsection{Thinking about sexuality}

\subsubsection{Activity 1. Discussing sexuality and culture}

To raise students' awareness about cultural contingency of sexuality and discuss the subject matter in more detail, the first activity required students to provide answers to the following questions: What is sexuality? What are some manifestations? What do you know about American and/or British society and the forms of sexuality there present? How different are they from the forms of sexuality produced in your own culture? What causes such differentiation? The answers were recorded and what follows is a short summary of the five-minute discussion.

Most of the students consider sexuality to be a physical manifestation of love or physical attraction, manifested through engagement in sexual and love relationships. Many students believed that Americans have a more overt way of showing physical attraction and less prejudices in forming relationships, although some showed reservations that these conceptualizations may be images we get from the media. Additionally, most students believed that the British culture is similar to their own by being conservative, although two students pointed that conservatism may be a thing from the past. A student explained cultural differences (freer expression of sexuality) between American and students' own culture pointing to the greater exposure of Americans and British to various genres of sexuality (text books, magazines, museums, and films) than Macedonians and/or Albanians.

\subsubsection{Activity 2. Evaluating stereotypes}

The second activity required students to express (dis)agreement and provide an opinion on five stereotype-based statements, each one relating to one of the videos (see Appendix 1 for details). The answers are given in Table 1. While the disagreement with the assumption may be considered only an index of questioning the ideas and values embedded in the statements, attempts to account for the attitude underpinning the disagreement may be taken as manifestations of students' awareness of cultural constructedness of sex-related assumptions, hence the account may be used as an instrument to measure students' critical reasoning.

Table 1. Summarised presentation of students' opinions on five stereotype-based statements 


\begin{tabular}{|c|c|c|c|c|c|}
\hline & \multicolumn{5}{|c|}{ Statements (Source) } \\
\hline & $\begin{array}{l}\text { Americans are } \\
\text { promiscuous } \\
\text { (Broad City) }\end{array}$ & $\begin{array}{c}\text { Children can } \\
\text { become sex } \\
\text { addicts (South } \\
\text { Park) }\end{array}$ & $\begin{array}{c}\text { British are } \\
\text { more sexually } \\
\text { conservative } \\
\text { than } \\
\text { Americans } \\
\text { (Monty } \\
\text { Python) } \\
\end{array}$ & $\begin{array}{l}\text { Mexicans are } \\
\text { sexually } \\
\text { uneducated } \\
\text { (George } \\
\text { Lopez stand } \\
\text { up) }\end{array}$ & $\begin{array}{c}\text { Gay men are less } \\
\text { hypocritical and } \\
\text { more open than } \\
\text { straight men } \\
\text { (Margaret Cho stand } \\
\text { up) }\end{array}$ \\
\hline 1 & $\begin{array}{l}\text { Promiscuity is } \\
\text { not culture } \\
\text { exclusive }\end{array}$ & $\begin{array}{l}\text { Sex addiction } \\
\text { develops through } \\
\text { practice, children } \\
\text { are } \\
\text { inexperienced }\end{array}$ & $\begin{array}{l}\text { The British } \\
\text { might have been } \\
\text { conservative in } \\
\text { the past }\end{array}$ & No answer & No answer \\
\hline 2 & Agree & Agree & No opinion & No opinion & Agree \\
\hline 3 & $\begin{array}{l}\text { It is a media } \\
\text { influenced } \\
\text { stereotype }\end{array}$ & Not a chance & $\begin{array}{l}\text { Yes, judging by } \\
\text { their behaviour }\end{array}$ & No answer & No answer \\
\hline 4 & \multicolumn{5}{|c|}{ ALL statements are generalisations and hence unacceptable } \\
\hline 5 & Agree & $\begin{array}{l}\text { Only in more } \\
\text { mature years }\end{array}$ & Do not agree & $\begin{array}{l}\text { I would not } \\
\text { generalise }\end{array}$ & Depends \\
\hline 6 & Agree & Agree & So-so & $\begin{array}{l}\text { Haven't met a } \\
\text { Mexican to } \\
\text { know }\end{array}$ & No answer \\
\hline 7 & \multicolumn{5}{|c|}{ "It is all dependent on who you ask". } \\
\hline 8 & $\begin{array}{l}\text { Partly agree, due } \\
\text { to the fact that } \\
\text { they are } \\
\text { introduced to sex } \\
\text { at early age }\end{array}$ & $\begin{array}{l}\text { No. Exposure to } \\
\text { sex acts does not } \\
\text { mean } \\
\text { engagement }\end{array}$ & $\begin{array}{l}\text { Agree, they } \\
\text { appear to be so }\end{array}$ & Disagree & Agree \\
\hline 9 & Not all of them & I don't think so & $\begin{array}{l}\text { Only when } \\
\text { drunk, maybe }\end{array}$ & I don't know & $\begin{array}{l}\text { Hypocritical maybe } \\
\text { but why open? Aren't } \\
\text { they afraid of speaking } \\
\text { openly? }\end{array}$ \\
\hline 10 & $\begin{array}{l}\text { Agree, sex is not } \\
\text { an issue of 'life } \\
\text { and death', as in } \\
\text { the Balkans }\end{array}$ & $\begin{array}{l}\text { Agree, they live } \\
\text { in a society that } \\
\text { is not strict and } \\
\text { experiment } \\
\text { earlier }\end{array}$ & $\begin{array}{l}\text { Definitely, they } \\
\text { are stiff as hell }\end{array}$ & $\begin{array}{l}\text { Yes, because } \\
\text { they are very } \\
\text { religious }\end{array}$ & $\begin{array}{l}\text { No idea how homos } \\
\text { are }\end{array}$ \\
\hline 11 & $\begin{array}{l}\text { The Spanish and } \\
\text { Czechs are more } \\
\text { promiscuous }\end{array}$ & $\begin{array}{l}\text { I doubt children } \\
\text { can become sex } \\
\text { addicts }\end{array}$ & $\begin{array}{l}\text { The British are } \\
\text { not only } \\
\text { English, but } \\
\text { also Indian }\end{array}$ & $\begin{array}{l}\text { I can't think } \\
\text { why they } \\
\text { wouldn't be } \\
\text { sex-educated }\end{array}$ & $\begin{array}{l}\text { Hypocrisy does not } \\
\text { relate to sex }\end{array}$ \\
\hline 12 & $\begin{array}{l}\text { Maybe more } \\
\text { sexually active } \\
\text { than } \\
\text { promiscuous }\end{array}$ & $\begin{array}{l}\text { More informed, } \\
\text { maybe some had } \\
\text { sex, but not } \\
\text { addicts }\end{array}$ & No idea & No idea & $\begin{array}{l}\text { I don't know much } \\
\text { about homosexuals }\end{array}$ \\
\hline
\end{tabular}

The majority $(n=8)$ do not agree that Americans are promiscuous because, in their own words, "promiscuity is not culture exclusive" and "it is a media constructed image". Other students believe that such statements are generalisations and their interpretations are context dependent. Four students agreed that Americans are promiscuous but only one respondent provided an explanation. According to the student, "sex is not a big fuss in the US as is in the 
Balkans", hence it is more readily and overtly practiced (S10). Although eight students disagreed with the idea that children can become sex addicts, only three demonstrated critical awareness by explaining that sex addiction is a result of exposure and/or practice of sex. On the other hand, three agreed that children are potential sex addicts, and one student explained this with an assumption that American culture has no strict sexual control. Reactions to the assumption that the British are sexually conservative reveal inconclusive results given that only four students disagreed, two had no opinion, and four agreed. Out of the first four, only two provided an account of the opinion, pointing to the out-of-date image of the British present in the video (S1) or to the ethnonymisation of all British citizens, even those of non-English origin (S11).

The reactions to the fourth statement "Mexicans are sexually under-educated" and the fifth "Gay men are more open and less hypocritical than straight men" revealed interesting results. Regarding the former, five respondents provided no answer, one of them pointing to the lack of experience with members of Mexican culture as an underlying reason for not being able to give an answer. Similarly, the lack of answers regarding the last statement ("Gay men are more open than straight") indicates that lack of contact with or information about homosexual culture may be the underlying reason. Based on the results, the hypothesis "Exposure to culture and its sexuality affects the ability to form an opinion to a certain extent" emerged and was included in the discussion following the watching of the videos. While watching the videos, students were asked to focus on: a) the way sexuality is presented, b) the stereotypes discussed, with the focus on the last two, and the c) role of humour. To facilitate discussion and data collection, students were asked to take notes.

\subsubsection{Activity 3. Reflection}

After having watched the videos, students were asked to use their notes and offer their opinion on the following three sets of questions:

- Q1 Do you think the representation of sexuality in the videos is a genuine expression of the culture's sexuality and its attitudes? If not, what other sources of representations of sexuality should be accounted for to get a better picture of culture's sexuality?

- Q2 Have any of your attitudes on the previous statements changed after watching the videos? How? Do you now have a more definite attitude on Mexican attitudes on sexuality and homosexuals' sexuality?

- Q3 Was sexuality represented in a funny way? Did humour help somehow to understand the issue better?

The answers were recorded with students' permission and analysed against intermediate categories relating to the three measured variables (questioning the embedded assumption, creation of new knowledge, and self-reflection). The (dis)agreement expressed to the first question and the alternative sources of representation of sexuality discussed helped register and measure students' critical awareness of the context-dependent, constructed nature of images of sexuality. The answers to the second question were used to identify attitude change potentially indicative of the creation of new synthesised knowledge and stimulating self-reflection, while the answers to the third question helped register the lubricating power of humour in the processes of critical examination of sexual stereotypes. The summarised answers to the questions are provided below:

Q1. The representations of sexuality in the five videos were considered deliberate exaggerations - one possible way of showing what sex is, among many others, such as news, films, literature, clothes, school books, etc. Students also showed awareness that perceptions of foreign cultures' sexuality are to a large extent influenced by the media, and to an extent by personal contacts. Thus, some argued that 'our' images of American sexuality are mostly a result 
of entertainment media, while 'our own' sexuality is mostly influenced by religion (an assumption more spread among Albanian students). Most likely due to strong religious feelings, some students were unwilling to talk about gay sexuality. To understand sexuality in its complexity, most students agreed that one needs to take into account other genres through which sexuality is constructed. Given the consensus that representations of sexuality are not genuine but rather context-dependent, including genre-dependent, students demonstrated critical understanding that each such representation is only a fragment, a piece of a puzzle that needs to be weighed against its origin and accounted in the totality of all such similar and dissimilar representations.

Q2. The majority of students admitted that there has been some change in their opinion, especially related to the lack of knowledge about Mexican culture and gay culture. After watching the videos, most believe that Mexican culture, similarly to their own culture, rests on traditional family values where sex is still considered a taboo topic, and hence Lopez's personification was taken as a genuine expression of such a state of affairs. As far as the gay culture is concerned, the discussion was heated because some male participants reacted in a homophobic manner towards the idea of male homosexuality rather than to its construction by Margaret Cho. In their case, the video and humour included therein had no effects on their attitudes. Female participants were more compassionate, confirming that "Cho somehow opened our eyes to think differently about straight men". Part of their reactions confirmed that more than learning something new, the video helped re-examine their own attitudes, very often blurred by the participation in the masculine, homophobic society they live in. The Monty Python video was considered to have no effect upon their opinions, as it was made in 1983, so it is non-representative of current British culture. As far as the representation of sexuality in Broad City and South Park is concerned, students admitted that it had no effect on their former attitudes.

Q3. Almost all students agreed that all videos were funny, except Broad City, which was repulsive to some, while the Lopez video was the funniest one because it was based on verbalised expression of a generally acceptable manifestation of sexuality, unlike gay sexuality in Cho or children's sexuality in South Park. Many students admitted that humour made them accept controversial issues more easily and, as one student pointed out, "you are sort of embarrassed that you are talking about sex in the presence of your colleagues, but it is ok because it is funny", while another student admitted that "if the videos were serious, I would not be freely talking about sex as I do now. It is like I have a permission to talk freely about sex, and that [happens] in school".

\subsection{Thinking about ethnicity}

\subsubsection{Activity 1. Class report on selected ethnicities}

Table 2 illustrates students' findings regarding the chosen cultures. The purpose of this activity was to raise students' awareness about the cultures and serve as an evaluative discourse of the listed stereotypes. The summarised results from the ten-minute discussion (audio-recorded) are as follows.

Table 2. Students' findings: general information and ethnic stereotypes.

\begin{tabular}{|l|l|l|}
\hline Ethnicities & General information & Stereotypes \\
\hline
\end{tabular}




\begin{tabular}{|l|l|l|}
\hline \multirow{2}{*}{ Mexicans } & $\begin{array}{l}\text { Old civilization, descendants of the Aztecs, } \\
\text { multicultural, very religious and family-dedicated, } \\
\text { similar humour to Macedonians, typical cuisine } \\
\text { (tacos and burritos), drug war, etc. }\end{array}$ & $\begin{array}{l}\text { Illegal immigrants, criminals, } \\
\text { lazy, dirty, easy girls }\end{array}$ \\
\hline Polish & $\begin{array}{l}\text { Formerly in union with Lithuanians, one of the few } \\
\text { who defeated Russians (1919-1921), successful } \\
\text { musicians, composers, writers, home of the bagels, } \\
\text { very religious }\end{array}$ & $\begin{array}{l}\text { Lack intelligence, cold, never- } \\
\text { smiling, love the beach }\end{array}$ \\
\hline Jews & $\begin{array}{l}\text { Self-perceived as God-created, religious, } \\
\text { conservative, self-proclaimed victims, but unfair } \\
\text { towards many (Palestinians), creators of the first } \\
\text { banking/value transfer system, largely successful in } \\
\text { business, matriarchal. }\end{array}$ & $\begin{array}{l}\text { Smart with money but also stingy, } \\
\text { successful, } \\
\text { self-proclaimed }\end{array}$ \\
\hline Estonians, greedy, self-complacent \\
$\begin{array}{l}\text { Baltic people ruled by Danes, Swedes, and Russians, } \\
\text { tech savvy (Skype), very 'poor' cuisine due to } \\
\text { shortage of food, high quality education, learn about } \\
\text { sex in primary school }\end{array}$ & $\begin{array}{l}\text { Cold, do not like to speak Russian, } \\
\text { quiet, humourless, slow }\end{array}$ \\
\hline
\end{tabular}

\subsubsection{Activity 2. Semi-structured discussion}

After the report, students were handed in copies of four jokes, each targeting one of the cultures chosen (Appendix 2) and a list of the following four questions:

- Q1 What are the stereotypes present in the jokes? Do they relate to the ones you provided? How?

- Q2 Choose two of the stereotypes and express your (dis)agreement with them.

- Q3 Who do you think created these stereotypes? Why?

- Q4 (How) Did reading before class affected your understanding and (dis)agreement with the joke and understanding of the targeted culture?

While the aim of the first question was to make sure there is consensus regarding the understanding of the jokes, the second and third questions aimed to record instances of questioning the stereotypes recognised in order to measure the critical understanding of the jokes. The last question was intended to measure the potential impact of (newly acquired) knowledge upon critical comprehension of stereotypes and the potential creation of new, synthesised knowledge.

Unanimously, students have identified the following four stereotypes: Mexicans are linguistically inept economic immigrants, Jews are penny pinchers, Poles are stupid, and Estonians are sexually inept. Compared to the stereotypes they have provided, the jokes confirm the stereotypes of Jewish stinginess and Poles' lack of intelligence, while Mexicans' knowledge of English and Estonians' lack of vivid sexual life were somewhat new to the students. Their opinions regarding the stereotypes vary. Most agree that the Mexican lower level of proficiency in English may relate to their status as immigrants beginning to learn the language of their host country, but they also pointed to the fact that second and third generation immigrants have a native-like mastery of English. Many students were not able to fully account for the origins of the Polish stupidity script, mostly confused by the great number of famous Poles, while one student intuitively speculated that 'Polish stupidity' may be an American product, used for lowwage immigrants in America, making them a laughing stock. There was a higher level of consensus that northern cultures are generally seen as cold and sexually less active. However, two students argued that it is not the frequency of intercourse that makes them look uninterested in sex but the expression of passion. Moreover, some students were concerned with how Estonians know about sex from an early age but do not practice it, according to the joke. It seemed that all students agreed that Jewish stinginess has more to it than meets the eye, 
explaining that none of them have met any Jew or representation of a Jew that speaks anything other than complete devotion to their own community and obsession with material wealth.

Many students were aware that stereotypes like these are created by other cultures, usually the ones who live nearby, not only to ridicule the target but, as phrased by a student, to "set them apart" - in other words, to guard the inter-ethnic boundaries and social hierarchies. Students generally agreed that the newly acquired information about these cultures helped them look, as they said, "wider", and see that even if Mexicans are portrayed as linguistically inept or lazy criminals, there are such people in other cultures as well. Some students admitted that what they read about Poles and Estonians in particular made them confused about the ascription of stupidity and sexual inactivity but that it also made them think who would benefit from such, as one student said, "non-validated" ascription. The conflict between the representations of the two cultures (Polish and Estonian) forced students to re-evaluate the latter (stupidity/sexual ineptness) in terms of former (culturally and intellectually renown/sexually educated). This, in turn, allowed them to question the grounds of ethnic stereotypes, understand their role as ethnic boundary markers, and produce a more complex understanding (knowledge) of the cultures discussed and the stereotypes attached.

Finally, almost all students confirmed that stereotypical Jewish stinginess is a result of years of (self)ridiculing discourse, be it prototypical Shakespeare's Shylock or Dickens' Fagin, Jewish self-deprecating humour (Jon Stewart, Jerry Seinfeld, Sarah Silverman), Jewish traditional image as bankers, masons, and misers, to name a few. Perhaps, as three students speculated, that was a reaction of jealousy by other cultures. In conclusion, students' answers manifested recognition and reaction to the mono-dimensionality of joke stereotypes which students debunked by offering counter-interpretations against the stigmatising nature of stereotypes. The knowledge they gained before the activity enabled them to juxtapose seemingly irreconcilable images (culturally acclaimed versus stupid), and construct a critical discourse based on the selfacquired knowledge they used as evaluative mechanism and basis for new knowledge.

\subsubsection{Activity 3. Joke target substitute}

In the last activity, students were asked to ascribe the stereotypes from the four jokes to their own ethnicity and comment on the result. Their reactions, in a most succinct form, are presented in Table 3. The motive for the substitute is to record students' perceptions of the applicability of the joke script to their own ethnic culture and to learn more about their ethnic self-perceptions.

Table 3. Ethnic self-evaluation (of the attributes' applicability)

\begin{tabular}{|l|l|l|}
\hline Scripts & \multicolumn{1}{|c|}{ Albanians } & \multicolumn{1}{c|}{ Macedonians } \\
\hline Stinginess & No & More egotist than stingy \\
\hline Stupidity & Yes (to an extent) & For some things \\
\hline Sexual inaptness & No way & No \\
\hline English language ineptness & No & No \\
\hline
\end{tabular}

The quality of stinginess was unanimously rejected by all Albanians on the grounds of them being raised in a culture that values solidarity, help, and support, one of the manifestations being the money given to the poor during Ramadan festivities. Macedonians felt that they are not openly stingy, yet they are less likely to offer support and help, especially to unknown individuals, as is the case with Albanians. Most of the Albanians believed that their ethnicity could be described as stupid mainly because of dominant, conservative, non-urban values embraced by the majority and the lack of open-mindedness. Interestingly, Macedonians see themselves as stupid due to rather different reasons, mainly for being easily prone to political manipulation and lack of national self-confidence. Both Macedonian and Albanian learners 
strongly disagree that their cultures are sexually inept. The problem with sexuality within the ethnic culture, as one student explained, is not the lack of desire or dexterity but of intimacy and discretion. As he explained, open manifestation of sexuality is discouraged and repressed. Finally, no student believed that either Macedonians or Albanians find it hard to learn English. Moreover, Albanian students maintained that being bilingual (both ample speakers of Albanian and Macedonian), they find it easy to acquire a new language.

\section{Discussion}

The attempt to elicit background knowledge and raise awareness about the cultural constructedness of sexuality through the first activity of a semi-structured discussion had limited success. It encouraged students to express their own knowledge of different cultural manifestations and perceptions of sexuality, allowing them to argumentatively account for their opinion. However, the activity gave them neither the opportunity to express and challenge their prejudices nor to acquire a new perspective, a new knowledge, so to say. In this regard, although the second activity did not register students' own prejudices, it did register students' awareness of some prejudices (American promiscuity, British sexual conservativism, and children's sex addiction) and manners of critical argumentation. More importantly, it registered an information lack that deemed itself an obstacle in making judgements about other stereotypes. Interestingly, no student attempted to produce any evaluation of these stereotypes at this point due to lack of background information, which can be taken as a tactful consideration of controversial issues, a sign of open mindedness, and avoidance to jump into rush conclusions by making rush judgements towards what they did not know, especially in terms of the statements related to Mexican and gay man sexuality. The two videos seem to have had different effects. While the Lopez video had a high informational value, helping students develop parallels with their own cultures, Cho's act did not change any prejudice among male students in particular, but it did stir some doubts, providing stimulation to take a fresh look among female participants. Objective-wise, the activities did raise the awareness of the constructed nature of human sexuality, enabling students to critically question the stereotypes presented, but, due to lack of time, it could not create an opportunity for students to first express and then examine their own prejudices regarding human sexuality. So, while new knowledge was actually not created, an opportunity to critically examine the old one was provided. The activities seem to fall the shortest when it comes to the objective of critical self-reflection since students were not specifically instructed or provided any opportunity to think and evaluate the sources and the process of their own thinking. The most relevant finding, however, was the contribution humour had to alleviating the inhibition to freely talk about sexuality.

Activities constructed over examples of ethnic stereotypes and humour allowed students to discuss the stereotypes and use newly gained knowledge to challenge them. However, while they were successful in understanding and debunking some stereotypes, such as Polish stupidity or Estonian sexual ineptness, with the help of the newly gained information and the use of historic, artistic, and social discourses as evaluative framework, most of them were aware of the prejudices they still may have regarding the Hebrew community. Albeit such awareness, they were not willing or ready to easily change them. In this sense, the purpose of becoming aware of one's own position was successfully accomplished, while changing it may take much more time and effort. Through the same activity, students revealed their awareness that joke-based stereotypes are social constructs that function as ethnic boundary keepers. Finally, while discussing the applicability of the four joke scripts (stinginess, stupidity, sexual ineptness, and language ineptness) to their own ethnic culture, students manifested the awareness of nonuniversality of some stereotypes (joke scripts). 


\section{Conclusion}

To sum up, if critical thinking encourages challenging prejudices, re-evaluation of knowledge, and critical self-reflection, then each of the activities contributed to a varying degree to the accomplishment of these ends. Some activities were more efficient in debunking stereotypes, others in re-examining and expanding existing knowledge. Perhaps the ambitious end of visible, quick, and, most of all, efficient change in the thinking about culture and its intimacies such as sexuality and ethnicity was not maximally accomplished, yet the class activities at least demonstrated that using humour to stir critical discussion is possible, and that humour may be beneficially used to encourage and stage such discussion. Thus, this study is not so much about humour as it is about thinking through humour. The success, however, can be enhanced by a more systematic integration of humour into teaching. One possible way to achieve this end is by designing and using more preparatory activities, such as collecting a set of prejudices and trying to challenge them with humour. Then, it is possible to introduce more in-class and extracurricular tasks that offer students exposure to evaluative discourses in order to sparkle their curiosity and desire for more information to serve as building blocks of deeper critical examination. Unfortunately, the accomplishment of a long-lasting effect takes a consistent effort over a longer period of time that an experimental design created only to identify the potential of humour is not by itself capable of doing. Nonetheless, this should not prevent instructors from trying, but only if they feel confident in the type of humour used. In this respect, this study is an encouragement for instructors to try to embrace the potential of humour as a great lubricant that can open the doors for what is otherwise socially censored, and make learners more critically aware of socially complex issues.

\section{Acknowledgements}

The author would like to express generous gratitude to all study participants without whom the study would have been impossible.

\section{Appendices}

\section{Appendix 1. Summaries of the videos underpinning the five stereotype-based statements}

"Americans are promiscuous" is a statement based on an episode from the US sit-com Broad City which follows the daily lives of two NY girls - Abbie and Alana. Much of the humour, sexual in nature, derives from their sexual fantasies and petit talks filled with overt comments on sexuality. In the episode chosen (Season 1, Episode 10), the girls are celebrating Alana's birthday in a fancy restaurant where they, among other topics, talk about 'fingering' and 'squirting'. The climax of the narrative is Abbie's discovery of a forgotten condom in her vagina and Alana's developing seafood allergy. The episode ends with them being thrown out of the restaurant, ending in a hospital emergency where their sexual innuendos continue.

"Children can become sex addicts" was elicited from the South Park episode "Sexual healing" which opens up with the problem of male adults' sexual addiction. The cause of the problem is humorously and satirically presented as coming from schoolchildren. Two of the main characters, Butters and Kyle, are 'diagnosed' as sex addicts and sent to a sex addiction clinic to be healed. There, they meet famous celebrities who have been 'infected' by sex addiction. Their alleged therapy reveals the hypocrisy of the system that tries to hide and protect sex offenders epitomized in the doctors' recommendation to the patients to avoid being caught. In the meantime, scientists, in a ludicrous manner, discover that money is what makes men 
sexually abusive. The discovery is presented to President Obama who offers an ever more weird account, according to which aliens have brought the virus to the rich.

"British are more sexually conservative than Americans" is a statement designed after watching the Monty Python video titled Sex Education. The narrative focuses on a sex education class in a boy school where the instructor is trying to teach and demonstrate the manners of lubricating a vagina as foreplay to a sexual intercourse. The bulk of the humour arises from the incongruous clash between devoid-of-feeling, technical language the instructor uses ("a man now starts making thrustic movement with his pelvic area, moving the penis up and down...") for an emotionally arousing activity such as sex and the lack of interest from his students. The peak of the narrative is the sexual intercourse between the instructor and his wife performed in class as a demonstration for students.

"Mexicans are sexually uneducated" comes from a stand-up routine by George Lopez where he ridicules conservative sexuality present in the Mexican American community by a personification of his grandmother who decided to openly speak about sex once he [Lopez] is old enough (34). The humour is a result from the granny's mispronunciation of sex-related expressions, among which 'filiz' for syphilis, 'condoloria' for chlamydia, 'VH1' for HIV, etc.

"Homosexuals are less hypocritical and more open than straight men" is rooted in Margaret Cho routine in which she explores the differences between straight and gay men, dramatizing the kind, caring, honest, and straightforward nature of gay men versus the hypocritical, brute nature of straight men. The humour is mostly based on her personification of different situations depicting the behaviours of the two groups of men.

\section{Appendix 2. Ethnic Jokes}

\section{Joke 1}

Why do Jewish men like to watch porno movies backwards? A: They like the part where the prostitute gives the money back.

\section{Joke 2}

A guy walked into a bar and said to the bartender: "I've got this great Polish joke." The bartender glared at him and warned him: "Before you go telling that joke, I think you ought to know that I'm Polish, the two bouncers on the door are Polish, and most of my customers are Polish." "OK," said the guy. "I'll tell it slowly."

\section{Joke 3}

Two Estonians are sitting by the campfire.

"Christmas is nice!" says one of them.

Half an hour later, the other one replies: "Yes, Christmas is nice, but a woman is even nicer!"

Another half an hour later, the first man replies: "Yes, a woman is better, but Christmas comes more often!"

\section{Joke 4}

US Border Patrol Agent catches an illegal alien in the bushes right by the border fence, he pulls him out and says "Sorry, you know the law, you've got to go back across the border right now." The Mexican man pleads with them, "No, noooo, Senior, I must stay in de USA! Pleeeze!" The Border Patrol Agent thinks to himself, "I'm going to make it hard for him" and says "Ok, I'll let you stay if you can use 3 English words in a sentence." The Mexican man of course agrees. The Border Patrol Agent tells him, "The 3 words are: Green, Pink, and Yellow. Now use them in a sentence." The Mexican man thinks really hard for about 2 
minutes, then says: "Hmmm, ok. The phone, it went Green, Green, Green, I Pink it up and sez Yellow?"

\section{References}

Banas, J. A., Dunbar, N., Rodriguez, D. \& Liu, S. (2011). 'A review of humour in educational settings: Four decades of research'. Communication Education 60 (1), pp. 115-144.

Bell, N. D. (2009). 'Learning about and through humour in the second language classroom'. Language Teaching Research 13 (3), pp. 241-258.

Bell, N. \& Pomernatz, A. (2014). 'Reconsidering language teaching through a focus on Humour'. EuroAmerican Journal of Applied Linguistics and Languages E-JournALL 1, pp. 31-47.

Bell, N. (2005). 'Exploring L2 language play as an aid to SLL: A case study of humour in NSNNS interaction'. Applied Linguistics 26 (2), pp. 192-218.

Belz, J. \& Reinhardt, J. (2004). 'Aspects of advanced foreign language proficiency: Internetmediated German language play'. International Journal of Applied Linguistics 14 (3), pp. 324-362.

Berk, R. (2000). 'Does humour in course tests reduce anxiety and improve performance?'. College Teaching 48, pp. 151-158.

Berk, R. (2002). Humour as an Instructional Defibrillator: Evidence-Based Techniques in Teaching and Assessment. Sterling. VA: Stylus Publishing.

Berk, R. \& Nanda, J. (2006). 'A randomized trial of humour effects on test anxiety and test performance'. Humor. International Journal of Humor Research 19 (4), pp. 425-450.

Berwald, J. (1992). 'Teaching French language and culture by means of humour'. The French Review 66, pp. 189-200.

Broad City. (2014). The Last Supper. Retrieved July, 162020 from https://www.dailymotion.com/video/x6nkqwf.

Broner, M. \& Tarone, E. (2001). 'Is it fun? Language play in a fifth-grade Spanish immersion classroom'. The Modern Language Journal 85 (3), pp. 363-379.

Bryant, J., Comisky, P. W., Crane, J. S. \& Zillmann, D. (1980). 'Relationship between college teachers' use of humour in the classroom and students' evaluations of their teachers'. Journal of Educational Psychology 72, pp. 511-519.

Bryant, J. \& Zillmann, D. (1989). 'Using humour to promote learning in the classroom', in McGhee, P. E. (ed.), Humour and Children's Development: A Guide to Practical Applications, New York: Haworth Press, pp. 49-78.

Cho, M. (2009). Gay Males/Straight Males. Retrieved July, 162020 from https://www.youtube.com/watch?v=TJPbEB5aKO4.

Cook, G. (2000). Language Play, Language Learning. Oxford: Oxford University Press.

Davies, E. C. (2003). 'How English-learners joke with native speakers: An interactional sociolinguistic perspective on humour as collaborative discourse across cultures'. Journal of Pragmatics 35, pp. 1361-1385.

Deneire, M. (1995). 'Humour and Foreign Language Teaching'. Humor. International Journal of Humor Research 8 (3), pp. 285-298.

Dormann, C. \& Biddle, R. (2006). 'Humour in game-based learning'. Learning, Media and Technology 31 (4), pp. 411-424.

Facione, P. (2011). Critical Thinking: What is it and why it counts. Retrieved July, 162020 from https://www.insightassessment.com/Resources/Importance-of-Critical-Thinking/ Critical-Thinking-What-It-Is-and-Why-It-Counts.

Freire, P. (1968). Pedagogy of the Oppressed. New York: Seabury Press. 
Frymier, A. B. \& Weser, B. (2001). 'The role of student predispositions on student expectations for instructor communication behavior'. Communication Education 50, pp. 314-326.

Frymier, A. B., Wanzer, M. B. \& Wajtaszczyk, A. M. (2008). 'Assessing students' perceptions of inappropriate and appropriate teacher humour'. Communication Education 57, pp. 266288.

Garner, R. L. (2003). 'Which came first, the chicken or the egg? A foul metaphor for Teaching'. Radical Pedagogy 5, 2. Retrieved July $16 \quad 2020$ from http://radicalpedagogy.icaap.org/content/issue5_2/04_garner.html.

Garner, R. L. (2006). 'Humour in pedagogy: How ha-ha can turn into aha!'. College Teaching 4, pp. $177-180$.

Giroux, P. (1983). Theory and Resistance in Education. Westport, CT: Bergin and Garvey Press.

Giroux, H. (1988). Teachers as Intellectuals: Toward a Critical Pedagogy of Learning. Westport, CT: Bergin and Garvey Press.

Gorham, J. (1988). 'The relationship between verbal teacher immediacy behaviors and student learning'. Communication Education 37, pp. 40-53.

Gorham, J.,\& Christophel, D. M. (1990). 'The relationship of teachers' use of humour in the classroom to immediacy and student learning'. Communication Education 39, pp. 46-62.

Gruner, C. R. (1967). 'Effect of humour on speaker ethos and audience information gain'. Journal of Communication 17, pp. 228-233.

Hackathorn, J., Garczynski, A. M., Blankmeyer, K., Tennial, R. D. \& Solomon, E. D. (2011). 'All kidding aside: Humour increases learning at knowledge and comprehension levels'. Journal of the Scholarship of Teaching and Learning 11 (4), pp. 116-123.

Hill, D. (1988). Humour in the Classroom: A Handbook for Teachers (and Other Entertainers!). Springfield, IL: Thomas Books.

Houser, M. L., Cowan, R. L. \& West, D. A. (2007). 'Investigating a new education frontier: Instructor communication behavior in CD-ROM texts do traditionally positive behaviors translate into this new environment?' Communication Quarterly 55, pp. 19-38.

Lopez, G. (2010). Sex Talk. Retrieved July, 162020 from https://www.youtube.com/watch?v=liQy1OYD1tk.

Judge, B., Jones, P. \& McCreery, E. (2009). Critical Thinking Skills for Education Students. Exeter: Learning Matters.

Mason, M. (ed.) (2008). Critical Thinking and Learning. Malden: Blackwell Publishing.

Monty Python. (1983) 'Sex education' in The Meaning of Life. Retrieved July, 162020 from https://www.youtube.com/watch?v=zRD0-7NSXd8.

Moon, J. (2008). Critical Thinking: An Exploration of Theory and Practice. Routledge: NY.

Medgyes, P. (2001). 'How's the for fun? The role of humour in the ELT classroom and ELT teaching materials', in Bax, M. \& Zwart, C.J.W (eds.), Reflections on Language and Language Learning: In Honour of Arthur van Essen, Philadelphia, PA: John Benjamins, pp. 105-118.

Neuliep, J. W. (1991). 'An examination of the content of high school teachers' humour in the classroom and the development of an inductively derived taxonomy of classroom humour'. Communication Education 40, pp. 343-355.

Saroglou, V. \& Scariot, C. (2002). 'Humour styles questionnaire: Personality and educational correlates in Belgian high school and college students'. European Journal of Psychology 1 (6), pp. 43-54.

Schmitz, J. R. (2002). 'Humour as a pedagogical tool in foreign language and translation Courses'. Humor: International Journal of Humor Research 15 (1), pp. 89-113.

Shor, I. (1992). Empowering Education: Critical Teaching for Social Change. Chicago: The University of Chicago Press. 
South Park (2010). Sexual healing. Retrieved July, 162020 from http://southparkzzzone.blogspot.com/2016/01/sexual-healing.html.

Stuart, W. D. \& Rosenfeld, L. B. (1994). 'Student perceptions of teacher humour and classroom climate'. Communication Research Reports 11, pp. 87-97.

Sudol, D. (1981). 'Dangers of classroom humour'. English Journal 70 (6), pp. 26-28.

Teslow, J. L. (1995). 'Humour me: A call for research'. Educational Technology Research and Development 43, pp. 6-28.

Torok, E. S., McMorris, R. F. \& Lin, W. C. (2004). 'Is humour an appreciated teaching tool? Receptions of professors' teaching styles and use of humour'. College Teaching 52 (1), pp. 14-20.

Trachtenberg, S. (1979). 'Joke-telling as a tool in ESL'. TESOL Quarterly 13 (1), pp. 89-99.

Wanzer, M. B. \& Frymier, A. B. (1999). 'The relationship between student perceptions of instructor humour and students' reports of learning'. Communication Education 48, pp. 4862.

Wanzer, B. M., Frymier, A. B. \& Irwin, J. (2010). 'An explanation of the relationship between instructor humour and student learning: Instructional humour processing theory'. Communication Education 59 (1), pp. 1-18.

Zillmann, D. et al. (1980). 'Acquisition of information from educational television programs as a function of differently paced humorous inserts'. Journal of Educational Psychology 72, pp. $170-180$.

Zillmann, D. et al. (1984). 'Effects of humorous distortions on children's learning from educational television'. Journal of Educational Psychology 76, pp. 802-812. 